\title{
Toplumsal Çatışmalar Bağlamında Sabahattin Ali’nin "Ayran" Hikâyesi
}

\author{
M. Onur HASDEDEOĞLU*
}

\section{$\ddot{\mathbf{O} z}$}

Toplumcu Gerçekçilik, Marksizm'in edebiyata bir yansıması olarak ortaya çıkar ve 1934'te Moskova'da düzenlenen Birinci Sovyet Yazarlar Birliği Kongresi’nin Maksim Gorki tarafından okunan sonuç bildirisi ile akımın ilkeleri belirlenmiş olur. Kısa bir süre içerisinde Türkiye'de de yansımasını bulan Toplumcu Gerçekçilik, ülkenin farklı siyasi ve sosyal koşullarına bağlı olarak Rusya'daki gelişme çizgisinden farklı biçimde ilerler. Bu sebeple Toplumcu Gerçekçilik, Türkiye'de daha çok köy ve köylü sorunlarını merkeze alan bir çerçeve içerisinde gelişim gösterir. Sabahattin Ali, Türk edebiyatının en bilinen Toplumcu Gerçekçi yazarlarından biridir. Onu diğer Toplumcu Gerçekçi yazarlardan farklı kılan esas husus ise, yazarın toplumcu gerçekçiliğin klişeleşmiş ilkelerine bağlı kalmayarak daha canlı kahramanlar yaratabilmiş olma başarısı ile doğrudan ilgilidir. Eserlerini genellikle toplumcu gerçekçiliğin etkisi doğrultusunda ezen-ezilen çatışması üzerine kurgulayan Sabahattin Ali, pek çok hikâyesinde bu çatışmanın toplumsal mesajını semboller üzerinden vermeyi tercih eder. Onun 1938 y1lında kaleme aldığ 1 "Ayran" hikâyesi de bu türden eserlerine tipik bir örnek teşkil eder. Bu çalışmada "Ayran” hikâyesi, Toplumcu Gerçekçilik akımının ilkeleri çerçevesinde sembolleştirdiği çatışma unsurlarından hareketle çözümlenmiştir.

Anahtar Kelimeler: Sabahattin Ali, Marksizm, Toplumcu Gerçekçilik, hikâye, çatışma

* Dr. Öğr. Üyesi, Kastamonu Üniversitesi, Fen-Edebiyat Fakültesi, Türk Dili ve Edebiyatı Bölümü, Kastamonu, Türkiye. Elmek: o.hasdedeoglu@kastamonu.edu.tr https://orcid.org/0000-0002-4920-2741 


\title{
Sabahattin Ali's "Ayran" Story in the Context of Social Conflicts
}

\begin{abstract}
Socialist-realism emerges as a reflection of Marxism in literature, and the tenets of the movement are determined by the final declaration of the First Soviet Writers Congress in Moscow in 1934, read by Maxim Gorky. Depending on the different political and social conditions in Turkey, within a short period of time Socialist-realism finds its reflection in Turkey and progresses differently from its development Russia. For this reason, Socialist-realism, makes progress within the framework centering the problems of villages and peasants. Sabahattin Ali is one of the well-known Socialist-realist writers of Turkish literature. The main point that distinguishes him from other Socialist-realist writers is directly related to his success in creating more vivid heroes by not adhering to the stereotypical principles of Social-realism. Sabahattin Ali, whose works are generally based on the oppressive-oppressed conflict under the influence of social realism, prefers to give the social message of this conflict through symbols in many of his stories. In this study, the story of "Ayran" which was written by Sabahattin Ali in 1938, has been analyzed according to the elements of conflict that are symbolized within the principles of Socialist-realism.
\end{abstract}

Keywords: Sabahattin Ali, Marxism, Socialist-realism, story, conflict 


\section{Extended Summary}

Socialist Realism, the projection of Marxism in literature, deals with the economic problems that are thought to be at the basis of all social events as the main problematic of the works. Socialist realist writers idealize the form of society based on Marxist philosophy against the form of society imposed by capitalism. For this reason, in socialist realistic works, ideological anxiety overcomes aesthetic anxiety.

Due to the fundamental differences in political and social conditions, Socialist Realism is reflected in Turkish literature from Russian literature differently. For this reason, Socialist Realist writers advance in Turkish literature by focusing on the problems of villages and peasants. However, Socialist Realist writers, who started to look at the events with a community-centered perspective, prefer to focus on the problems of geography and society from a realistic and critical perspective.

Sabahattin Ali, one of the most competent names in socialist realism in Turkish literature, is an artist who has succeeded in creating living heroes in his works thanks to his powerful observer ability. In this way, the author has reached the limits of social realism and observer and critical realism. In this study, the story named "Ayran", which is analyzed by taking the symbols of social realism as a center, is a work that has exceeded the limits of social realism. After analyzing the story by centering the symbols of Social Realism, the conclusions reached can be summarized as follows:

1. From the beginning of the story it is possible to encounter Sabahattin Ali's high observation and linguistic ability. The author provides an awareness of the gap between the village and the city life through the space depiction he made at the beginning of the story.

2. The train symbolizes the modern age and therefore capital order. The station building which resembles a piece of stone thrown there and the railroad lying in the middle of the vast cavity are the only vehicle that connects civilization with primitive. The profile of the passengers inside when the train stops at the station also proves this symbol. On the other hand, while running along the train, Küçük Hasan is looking for "well-situated villagers", "tradesmen without tie", "soldiers 
on leave", that will not hesitate to drink ayran from tin mugs. The symbols used by the author in these sentences are extremely important in referring to social classes.

3. The long-necked, helmeted, gray-haired train traveler, who asks ayran, is the most concrete example of the capital-labor conflict within the social distortion created by the capital order imposed by civilization and constitutes the main problematic of the story. While Küçük Hasan represents labor and the oppressed class, the train traveler is the absolute symbol of capitalism and the oppressing class. Socialist realistic literature always centered the oppressed class and opposes it to the distorted order created by labor and exploitation. Sabahattin Ali constructs the relationship between Küçük Hasan and the train passenger in order to emphasize this distortion.

4. All the elements that form the environment of Küçük Hasan reinforce the oppressor-oppressed conflict within this distorted order. As a matter of fact, the only capital of Küçük Hasan to make ayran and make money is an old and skinny goat. Küçük Hasan's greatest fear is that two hungry little stomachs in the house eat this goat in his absence. In this respect, Küçük Hasan and his two dependents are not civilized and humanized due to the distorted order created by capitalism. Küçük Hasan and his two brothers act with primitive instincts throughout the story because of the unfair treatment of modern life and depriving them of the wide opportunities it offers. In fact, the system has almost mechanized Küçük Hasan, who is obliged to make money with his labor.

5. The situation of Küçük Hasan's mother is a bitter expression of another distortion in society. In the story, the mother stated that she worked as a cleaner in the sub-district center, probably had to sell her body in order to maintain her life and take care of her children, and her only capital, her body, was exploited by men. For this reason, women and children are not accepted and excluded by their environment. The biggest reason for this is the injustices in the society.

As a result, in the "Ayran" story, Sabahattin Ali reveals the oppressiveoppressed conflict, one of the most fundamental elements of Social Realism, by symbolizing the concepts of capitalism and labor in various ways. The fact that the author fictionalizes the protagonists in his works based on his realistic observations takes him to an observer and critical realism dimension, stripping him of the clichés of Social Realism. For all these reasons, Sabahattin Ali stands out as one of the most original artists of Socialist Realistic Turkish literature. 


\section{Giriş}

Marksizm'in edebiyattaki izdüşümü olan Toplumcu Gerçekçilik, bütün toplumsal olayların temelinde yer aldığı düşünülen iktisadi meseleleri eserlerin temel sorunsalı olarak ele alır. Toplumcu gerçekçi yazarlar, kapitalizmin dayattığ1 toplum biçimine karşı, Marksist felsefeye dayalı toplum biçimini idealize ederler. Bu sebeple, toplumcu gerçekçi eserlerde ideolojik kaygı, estetik kayg1nın önüne geçer.

Toplumdaki problemlerin asıl sebebinin halkın ekonomik durumuyla alakalı olduğunu düşünen toplumcu gerçekçi yazarlar, eserlerinde konu olarak genellikle emek-sermaye, işçi-işveren, köylü-ağa, ezilen-ezen çatışmalarından faydalanarak, toplumdaki sınıfsal farklılığı eleştirirler. Emeğin yüceltilmesi, bireye birey olarak değer verilmesi ve ekonomiye dayalı sınıfsal farklılıkların ortadan kaldırılması toplumcu gerçekçi yazarın daima vurguladığı hususlardır. $\mathrm{Bu}$ sebeple toplumcu gerçekçi yazarlar, sanatı ideolojinin halka benimsetilmesi yolunda bir araç olarak görürler. Lukacs, bu durumun Marks'ın tarih felsefesinin edebiyata bir yansımasının doğal bir gereği olduğunu ifade eder: "Marksçı tarih felsefesi insanı bir bütün olarak çözümler, insan evriminin tarihini, gelişimin çeşitli dönemlerinde bütünlüğe klsmen ulaşma ya da ulaşamama olgusu ile birlikte bir bütün olarak düşünür. Bütün insani ilişkileri yöneten gizli yasalar ortaya çıkarmaya çalışır. Yani toplumcu hümanizmin amacı noksansız insani kişiliği yeniden kurmak ve onu sınıfl toplumda uğradı̆̆ sapmalardan ve dă̆llmalardan kurtarmaktır." (Lukacs 1987, 12)

Lukacs'ın yukarıda alıntılanan görüşleri Toplumcu gerçekçiliğin neden ezen-ezilen çatışması başta olmak üzere toplumsal ve sınıfsal çatışmaları merkeze aldıklarını açıklar.

Devrim sonrası her milletin kendi geleceğini kurma hakkına sahip olduğunu belirten Bolşevik yönetiminin amac1, farklı etnik kökenler ile sosyalist devrim arasındaki bağı kuvvetlendirmek ve bu milletleri sosyalizme hizmet edecek konuma getirmektir. (Dalar 2019: 242) İlk örnekleri 20. yüzyılın 
başlarında 1917 Ekim Devrimi’nin öncesinde görülmeye başlanan Toplumcu Gerçekçiliğin ilkeleri, 1934’te Moskova'da düzenlenen Birinci Sovyet Yazarlar Birliği Kongresi’nde belirlenir ve bu tarihten itibaren toplumcu gerçekçilik, Sovyet Rusya'nın resmi sanat görüşü olarak kabul edilir. Akımın ilkeleri Maksim Gorki tarafından dört madde halinde özetlenir. Buna göre:

1. Toplumcu Gerçekçilik daha önceki eleştirel gerçekçilikten farklı olarak programatik bir edebiyattır ve bir tezi vardır.

2. Bu edebiyatta insanı belirleyen en temel öge kolektivizmdir: "Sosyalist bireysellik ancak kolektif emek içinde gelişebilir."

3. Toplumcu gerçekçi edebiyatta iyimser bir bakış açısı egemendir: "Yaşam eylemdir ve yaratmaktır. Yeryüzünde yaşayan insanın ulaşmak isteyeceği en son erek yeryüzünde yaşamak mutluluğudur."

4. Bu edebiyat eğitsel bir işlevle yüklüdür: "Sosyalist bireyselliğin geliştirilmesi bu edebiyatın ana amacıdır. (Kahraman 2004, 58)

Estetik olmaktan çok ideolojik bir edebi anlayış olan toplumcu gerçekçilik, bu sebepten dolayı Sovyet Rusya'nın Marksist-Leninist ideolojisinin sanattaki uygulaması olarak gelişir. (Oktay 2000, 13) Dünya siyasi ve toplumsal koşullarının zaman içerisinde gösterdiği değişiklik ise Toplumcu Gerçekçi sanatçıların toplumsal ve estetik görüşlerine yansır. Toplumcu Gerçekçilik ve bu akımın sınırları, Ernest Fischer başta olmak üzere pek çok kuramcı tarafından tartışılır. Nitekim Fisher, "gerçekçilik" teriminin yarattığı sakıncayı hesaba katarak, bu akıma "Toplumcu Gerçekçilik" yerine "Toplumcu Sanat" denmesini daha doğru bulduğunu ifade eder. (Moran 2003, 64)

Türkiye'de ise toplumcu gerçekçilik, Rusya'da geliştiğinden daha farklı bir çizgide gelişim gösterir. Siyasi ve sosyal şartların farklılığı, Türklerin sosyal ve siyasi yapılanmasında yüzyıllar boyunca sınıflı bir toplum ortaya çıkmasına müsaade edilmemesi dolayısıyla, Toplumcu Gerçekçilik akımı Türk edebiyatında daha çok köy ve köylü sorunlarını merkeze alarak ilerler.

Osmanlı'nın son yüzyılında, devleti ayakta tutmak ve çöküşü engellemek adına Osmanlıcılık, İslâmcılık, Türkçülük ve Batıcılık gibi pek çok ideolojik görüş ortaya atılır. Bilhassa Balkan Savaşları ve hemen ardından başlayan I. Dünya 
Savaşı'nın etkisiyle Osmanlıcılık ve İslâmcılık hızla kan kaybederken, Türkçülük akımı toplum ve edebiyat üzerinde giderek daha etkili olur. Bu dönemde yaşanan acıların etkisiyle Türkçülük düşüncesi de form değiştirmeye başlar. Özellikle Savaşın sonuna doğru gittikçe laikleşen ve Turancılıktan Anadoluculuğa doğru evrilen bir Türkçülük ve milliyetçilik düşüncesi yükselir. (Köroğlu 2016, 33)

Milli edebiyat döneminde yazarlar, romantik bir anlayış çerçevesinde yüzlerini Anadolu'ya dönerler ve Cumhuriyet'in ilk yıllarında bu romantik anlayışın etkisiyle Türk edebiyatında "Anadoluculuk” adı verilen bir akım ortaya çıkar. Bu ruh hali içinde, aydınların zihinlerinde Anadolu, bir toprak parçasının adı olmaktan ziyade, bir felsefenin adı, bir sosyolojik bakış açısının özeti, bir ideoloji, bir tutkuya dönüşür. (Yalçın 2003, 83)

II. Dünya Savaşı'na doğru hızla sürüklenen dünya yaşanan ekonomik kriz Türkiye'yi de derinden etkiler. Henüz emekleme aşamasında olan Cumhuriyet Türkiye'si, gelişmiş bir tarım ve sanayisinin olmaması dolayısıyla bu kriz sürecinde derinden etkilenir. Böylelikle, Toplumcu Gerçekçiliğin de etkisiyle Anadoluculuk akımının romantik coğrafya ve tabiat algısı, Toplumcu Gerçekçi eserlerde yerini Anadolu köylüsünün problemlerinin gerçekçi izlenimlerine b1rakır. Toplumcu Gerçekçiliğin Türk edebiyatında ilk yansımaları şiir alanında Nazım Hikmet'le vücut bulur. Sadri Ertem'in 1928 yılında yayımlanan 'Bacay1 İndir Bacayı Kaldır” hikâyesi ise bu akımın Türk nesrindeki ilk örneği olarak kabul edilir. Sabahattin Ali ise Toplumcu Gerçekçiliğin Türk edebiyatının en yetkin ismi olarak ön plana çıkar.

\section{Toplumsal Çatışmalar Bağlamında Sabahattin Ali’nin "Ay- ran" Hikâyesi}

Sabahattin Ali, mesleği dolayısıyla Anadolu'da edindiği izlenim ve gözlemlerini eserlerine gerçekçi bir biçimde aktarmayı başarmış bir yazardır. ${ }^{1}$ Toplumcu gerçekçi bir yazar olarak Sabahattin Ali'nin pek çok eserinde iktisadi meseleler ile buna bağlı toplumsal problemler işlenir. Yazar, 1938 yılında kaleme aldığı ve Yeni Dünya ${ }^{2}$ kitabı içerisinde yer alan “Ayran” hikâyesinde de ekonomik adaletsizliğin doğurduğu bir ezen-ezilen çatışmasını merkeze alan trajik bir hikâye ortaya çıkartır. "Ayran” hikâyesinin girişi bu gerçekçi gözlemin en 
etkileyici örneklerinden birini teşkil eder: "Köyden istasyona giden yol, eriyen karlarla diz boyu çamurdu. İki mızrak boyu yükselen güneş, tarlaları hâlâ örten karların üzerinde pırıltılarla ve göz kamaştırarak yanıyor, fakat yoldaki pis su birikintilerine vurunca donuk sarı bir renk alıp boğuluyordu.” (2007: 32)

Yazarın Anadolu bozkırına dair yaptığı bu betimleme, Anadolucuların alışılagelmiş romantik betimlemelerinden son derece farklı bir çizgidedir. Nitekim hikâyenin ana mekânlarından birini teşkil eden ve "iki tarafi çıplak dağlarla çevrilen bu upuzun ovanın tam orta yerinde yapayalnız duran ve etrafindaki yapraksı akasyalarla daha zavallı görünen” İstasyon binası da yazarın ifadesiyle "oraya rastgele atılmış bir taş parçasını" andırır. Bu şekliyle hikâye, daha başlangıcından itibaren, Anadolu atmosferini destansı, masalsı biçimde, işleyen lirik eserlerden ayrılır. Tren; medeniyetin, modernizmin, demir çağının ve dolayısıyla sanayileşmenin bir sembolüdür. Oysa bu hikâyeye mekân teşkil eden bu coğrafya, medeniyetten uzak tasviri ile dikkat çeker. Yazara göre, günde iki defa geçen posta treni bile, "ne diye bu manasız yerde duruyorum” diye hayret eder gibidir. Yani kasabadaki istasyon binası ve o istasyonun varlık sebebi olan tren, köy ile şehri birbirine bağlamaya vasıta teşkil eden yegâne mekândır. Ancak yazar, çarpıcı betimlemesi ile modern ile geleneksel arasındaki uçurumu açık biçimde ortaya koyar.

Hikâyenin başkahramanı Küçük Hasan'ın ailesi, biri iki, öteki beş yaşında olan iki kardeşi ve annesinden ibarettir. Annesi de dört saat uzaklıktaki nahiye merkezinde hizmetçilik yaptığ 1 ve eve haftada bir kez geldiği için Küçük Hasan, tek sermayesi olan cılız ve ihtiyar keçinin sütünden yaptığı ayranı, yaz-kış demeden, sırtına yüklediği kocaman gügümle iki saatlik mesafedeki istasyonda satarak, iki kardeşine bakmakla yükümlü, zavallı bir çocuktur. Her haliyle kapitalist dünya düzeninin kendisine adeta hiçbir fırsat tanımadığı, bozuk toplumsal düzenin kurbanı olmaya mahkûm bırakılmış insanların temsilciliğini üstlenir. Yazar hikâye boyunca onun bu çaresizliğini hissettirecek ince detaylar ile hikâyede vereceği mesajın etkisini kuvvetlendirmek için zemin hazırlar.

Hasan, bu bozuk düzenin, insan olma hakkını elinden aldığ 1 , hatta ona bu hakkı hiç tanımayarak adeta makineleştirdiği zavallı bir mahlûktur. Zira Hasan, soğuk kış gününde, sırtında kocaman güğümle istasyona ulaşmaya çalışırken ne 
nahiye merkezindeki annesini, ne evde kendini bekleyen iki küçük kardeşini, ne de ayranını satıp satamayacağını düşünmektedir. O esnada düşündüğü tek şey, “bu yolu tekrar yürümek, geri dönmek mecburiyeti[dir]” (2007: 33) Nitekim Hasan, istasyona ulaştıktan bir süre sonra, yaklaşan trenin düdügünü duyduğunda da insandan ziyade makine gibi harekete geçer: "Küçük Hasan, kurulu bir makine gibi, güğümü ve maşrapayı yakalayarak trenin boyunca koşmaya ve başını pencerelere kaldırarak: "Ayran, ayran, temiz ayran!” diye bağırmaya başladi.” (2007: 34)

Küçük Hasan, toplumcu gerçekçiliğin idealize ettiği hırslı, çarpık düzeni değiştirmeye azmetmiş isyankâr kahramanlardan değildir. Onun bir yandan tren boyunca baştan sona koşup, bir yandan “Ayran, ayran, temiz ayran!” diye bağırdığg esnada düşündüğü tek şey, hiç olmazsa dört bardak ayran satabilmektir. Zira Hasan, dört bardak ayran sattığı takdirde kazanacağ1 on kuruşla, evde aç gözlerle kendisini bekleyen kardeşlerine bir kara ekmek götürebilecektir.

Hasan'ın umutlarının tükendiği anda, trenin üçüncü mevki vagonlarından birinin penceresi açılır ve "uzun boyunlu, kasketli, kır bıyıklı bir baş" uzanarak “Ver bakalım bir tane!" diye seslenir; Hasan, soğuktan titreyen elleriyle maşrapayı uzatır. Adam ayranı bir dikişte bitirir, bir maşrapa daha ister. Onu da içince, yeleğinin cebinden çıkardığ 1 onluğu uzatarak, "Ver beş kuruş!’” der. Cebinde hiç para olmayan Hasan, on kuruşu bozdurmak üzere istasyon memurunun yanına koşar; ancak istasyon memuru Hasan'1 duymazdan gelerek hareket düdüğünü çalar ve tren harekete geçer. O esnada on kuruşun sahibi, "Gelsene ulan!" diye bağırarak Hasan'1 çağırır, parasını geri ister; Hasan, hiç tereddütsüz, parayı adama uzatır. Küçük Hasan'ın eve bir kara ekmek götürebilmek için kazanmayı umut ettiği meblağ olan on kuruşu yeleğinin cebine koyan adamın, "Yok çeyreğim, ne yapalım!” dedikten sonra hareket halindeki trenden başını uzatarak, helallik istemesi ise son derece çarpıcıdır: "Vagon küçük Hasan'dan beş altı adım uzaklaşmıştı. Uzun boyunlu adam, pencereden sarkarak: 'Hey, çocuk, hakkını helal et!' diye bağırdı. Küçük Hasan hiçbir şey anlamıyormuş gibi bakakalmıştı. Tren hızlanıp uzaklaşıyordu. Tekerleklerin gürültüsü arasında adamın sesi tekrar duyuldu: 'Helal et bakayım, helal et!.. Hadi!'”' (2007: 36)

Trendeki adam, Küçük Hasan’a karşı davranış biçimi ile emeğin kar- 
Ş1sında sermayenin ve dolayısıyla kapitalizmin mutlak bir temsilcisidir. Küçük Hasan, büyük imkânsızlıklar içerisinde ürettiği ayranını satarak hayatını kazanan ve evini geçiren bir emekçidir. Buna karşılık trendeki adam, Hasan'ın bu emeğini sömürür. Oysa adamın verdiği on kuruş, Küçük Hasan'ın eve ekmek götürebilmek için ihtiyaç duyduğu ve fazlasını kesinlikle hayal bile etmediği meblağdır. Hasan, kazanmayı arzuladığı on kuruşu eline geçirmiş, tren de hareket etmiştir. Bu koşullar içerisinde adamın trenden inerek on kuruşunun peşine düşmesi mümkün değilken, Küçük Hasan, parayı sahibine iade etmeyi tercih eder. Zira onun hakkı olan tutar beş kuruştur ve on kuruşu geri vermediği takdirde Küçük Hasan, haksız kazanç elde etmiş olacaktır. Küçük Hasan, toplumcu gerçekçi eserlerde sıklıkla işlenen ve düzene başkaldırması yönünden idealize edilmemiş olmasına karşılık, dürüstlük ve ahlak yönünden idealize bir kahramandır. On kuruşunun peşine düşen ve o paraya asıl ihtiyaç duyan taraf olan Küçük Hasan'ın elinden parasını geri alan tren yolcusu ise mutlak bir emek sömürücüsüdür.

Kapitalizm Hasan'1 sadece makineleştirmekle kalmaz; onu aynı zamanda hayvanlaştırır. İnsanoğlu, tanrı tarafından konuşma kabiliyetiyle şereflendirilmiş ve bu yönüyle diğer bütün canlılardan ayrı tutulmuş bir varlıktır. Onun bu yeteneği, gelişen iletişim kurma becerisi ve içgüdüsel olarak daima kendini geliştirme arzusu yüzyıllar içerisinde medeniyetin doğmasına ve gelişmesine olanak sağlamıştır. Medeniyet, insana "insanca” yaşama hakkını sunar. Ancak Sanayi Devrimi sonucunda hızlanan makineleşme ve kapital ekonomik sistemin etkisiyle oluşan işçi sınıfı, adeta yeni bir kölelik sistemi doğurur ve bu yeni toplumsal düzen, insan haklarının yeniden sorgulanmasını mecbur kılar.

$\mathrm{Bu}$ yönden bakıldığında yalnız Küçük Hasan değil, kardeşleri ve hatta annesi de iletişim kurma kabiliyetlerinden mahrum bırakılmış ve koşullar dolayısıyla kendini gerçekleştirememiş, diğer bir anlamda "insanlaşamamış" varlıklardır. Hikâye boyunca ayran satmak için istasyonda bağırdığı kısım dışında, Küçük Hasan neredeyse hiç konuşmaz. Nitekim iyiden iyiye hızını artıran karın altında, çaresizlik içinde akşam beş trenini beklemeye karar veren, fakat durmasiyla hareket etmesi bir olan trende ayran satacak kimse bulamayan ve eli boş dönmeye mecbur kalan Küçük Hasan, “hiçbir şey düşünmeden, hiçbir şey 
hissetmeden ve bir hayvan gibi yolunu alışkanlıkla bularak” yürüdüğü dönüş yolunda kurtlar etrafını sardığında dahi girtlağından “ $A$... A...Aaah” şeklinde, “Ana... Ana! ”ya benzeyen birtakım anlaşılmaz sesler çıkartır. Bu durum Küçük Hasan'ın nasıl insanlıktan/medeni yaşama haklarından mahrum bırakıldığının ve yavaş yavaş nasıl "hayvanlaştı̆̆ının” bir göstergesidir.

Hasan'ın hiç medeniyet yüzü görmemiş iki küçük kardeşinin hikâyede insandan ziyade hayvana benzer biçimde tasvir edilmesi ise bu bakımdan son derece çarpıcıdır:

"Biri iki, öteki beş yaşında olan bu siska çocukların bütün işleri, basık tavanlı bir damdan ibaret olan evde ellerine ne geçerse yemekten ibaret gibiydi. Küçük Hasan her gün yoğurt çalmak için kendisine lazım olan mayayı onların yetişemeyeceği ve bulamayacă̆ bir yere [...] saklamaya mecbur oluyor ve her gün, istasyonda bulunduğu sırada, bu iki aç midenin, kendileriyle aynı çatı altında aynı açlığı çeken ihtiyar keçiyi bile yiyeceklerinden korkuyordu.

Çok akşamlar, koltuğunun altında getirdiği ekmeği ortaya koyarak ayran boşaltmak için bir toprak çanak getirmek üzere ocağın yanındaki köşeye gider, sofra başına döndüğü zaman o balçık gibi ekmekten ortada bir şey kalmadığını dehşetle görürdü.” (2007: 34-35)

Yukarıdaki alıntıda da görüleceği üzere, çarpık düzen Küçük Hasan gibi kardeşlerinin de elinden insanca yaşama hakkını almıştır. İçgüdüleriyle yaşayan bu çocukların davranış biçimi insandan çok hayvanı andırmaktadır. Nitekim Küçük Hasan'1 asıl dehşete düşüren şey, onların hiç doymayan midelerinden ziyade, "eli boş olarak eve döndüğü zaman, bu iki slska mahlûkun kendisine nasıl parlak ve büyümüş gözlerle ve nasıl sonsuz bir kinle baktığını” (2007: 35) görmektir.

Hikâyede ezen-ezilen çatışmasını Küçük Hasan'ın annesinin hayatında da farklı bir perspektiften görmek mümkündür. Yazar, annenin yaşadığ1 dramı anlatmaktan ziyade sezdirmeyi ve okuru kadının bozuk toplum düzeninde nasıl ezildiği üzerine düşündürmeyi tercih eder. Küçük Hasan’1n dört saat uzaklıktaki nahiye merkezinde hizmetçilik yapan annesi, çocuklara ancak iki gün yetecek kadar erzakla eve haftada bir kere gelir, birkaç saat durduktan sonra gider. Hikâyede anne hakkında verilen malumat ancak bu kadardır, ancak "hayatı istasyonda ayran satmaktan ve küçük kardeşlerini beslemekten ibaret" zanneden 
Küçük Hasan'ın duyduğu bazı endişeler, annenin anlatılmayan hayatına dair çarpıc1 ipuçları verir: "Ya anam yine günün birinde eve gelip birkaç gün yatar, iniltiler içinde ve kendi kendine bir çocuk daha doğurur, beş on gün sonra onu da başıma bırakarak giderse, diyordu... Bu yeni misafiri de doyurmak kendisine düşecekti." (2007: 37)

Buradan Küçük Hasan ve diğer iki kardeşinin her birinin babasının farklı olduğu sonucu çıkıyor ve zihinlerde anneye dair iki ihtimal canlanıyor: 1. Annenin Küçük Hasan'a hizmetçi olarak çalıştığını söylemiş, fakat gerçekte bedenini satarak para kazanıyor olması, 2. Annenin hizmetçilik yaptığı evlerde tecavüze uğramas1.

Nitekim annenin Küçük Hasan'a bir kez olsun babasından veya herhangi bir akrabadan bahsetmemiş olması, köydeki komşuların da onların evinden uzak kalmayı tercih etmeleri, hayatta kalma mücadelesi veren bu üç küçük çocuğun kaderine terk edilmişliği, birinci seçeneğin mutlak gerçeğe daha yakın bir ihtimal olduğunu gösterir. Sebep her ne olursa olsun, bu durum, toplum yapısının bozukluğunun ve hayatını kazanmaya çalışan kadının nasıl ezildiğinin bir göstergesidir.

\section{Sonuç}

Marksizm'in edebiyattaki izdüşümü olan Toplumcu Gerçekçilik, kapitalizmin dayattığı toplum biçimine karşı, Marksist felsefeye dayalı toplum biçimini idealize eder. Bu sebeple, toplumcu gerçekçi eserlerde ideolojik kaygı, estetik kaygının önüne geçer. Siyasal ve sosyal koşullardaki temel farklılıklar dolayısıyla Toplumcu Gerçekçilik, Türk edebiyatına Rus edebiyatından farklı biçimde yansır. Bu sebeple Toplumcu Gerçekçi yazarlar Türk edebiyatında daha çok köy ve köylü sorunlarını merkeze alarak ilerler. Ancak olaylara toplum merkezli bir bakış açısı ile bakmaya başlayan Toplumcu Gerçekçi yazarlar, romantik Anadoluculuk anlayışından sıyrılarak, coğrafyanın ve toplumun sorunlarına gerçekçi ve eleştirel bir perspektifle eğilmeyi tercih ederler.

Toplumcu Gerçekçilik akımının Türk edebiyatındaki en yetkin isimlerinden biri olan Sabahattin Ali, güçlü gözlemcilik kabiliyeti sayesinde, eserlerinde canlı kahramanlar yaratabilmeyi başarmış bir sanatçıdır. Yazar, bu sayede 
toplumcu gerçekçiliği de sınırlarını aşarak gözlemci ve eleştirel gerçekçiliğe de ulaşabilmiştir. Bu çalışmada toplumcu gerçekçiliğin sembolleri merkeze al1narak çözümlenen "Ayran” hikâyesi de toplumcu gerçekçiliğin sınırlarını aşabilmiş bir eserdir. Hikâye, Toplumcu Gerçekçiliğin sembolleri merkeze alınarak çözümlendikten sonra ulaşılan sonuçlar şu şekilde özetlenebilir:

1. Hikâyenin başından itibaren Sabahattin Ali’nin yüksek gözlem ve dil kabiliyeti ile karşılaşmak mümkündür. Yazar, hikâyenin başında yaptığı mekân tasviri ile köy ve şehir hayatı arasındaki uçurum hakkında farkındalık sağlar.

2. Tren, modern çağı ve dolayısıyla kapital düzeni sembolize eder. Oraya atılmış bir taş parçasını andıran istasyon binası ile uçsuz bucaksız boşluğun ortasında uzanan demiryolu ise medeniyet ile ilkeli birbirine bağlayan yegâne vasıtadır. Tren istasyonda durduğunda içindeki yolcuların profili de bu sembolü kanıtlar niteliktedir: "Trenin bütün camları kapalıydı, açık olan bir ili tanesinde de boyalı saçlı, yün bluzlu kadınlar duruyordu." (2007: 34) Küçük Hasan ise tren boyunca koşarken bir yandan pencereleri gözleyerek teneke maşrapadan ayran içmekten imtina etmeyecek "hali vakti yerinde köylüler, boyunbağsiz esnaflar, izinli giden askerler” aramaktadır. Buradaki "boyunbağsız esnaf”, "boyalı saç", "yün bluz” ifadeleri, yazarın toplumsal statülere ilişkin ince göndermeleridir.

3. Küçük Hasan'dan ayran isteyen uzun boyunlu, kasketli, kır saçlı tren yolcusu, medeniyetin dayattığı kapital düzenin yarattığı toplumsal çarpıklık içerisinde sermaye-emek çatışmasının en somut örneğidir ve hikâyenin başlıca sorunsalını teşkil eder. Küçük Hasan, emeği ve ezilen sınıfı temsil ederken, tren yolcusu kapitalizmin ve ezen sınıfın mutlak sembolüdür. Toplumcu gerçekçi edebiyat daima ezilen sınıfı merkeze alır ve bunun karşısında emeğin-sömürünün yarattığı çarpık düzeni eleştirir. Sabahattin Ali, Küçük Hasan ile tren yolcusu arasındaki münasebeti bu çarpıklığ 1 vurgulamak amacıyla kurgular.

4. Küçük Hasan'1n çevresini oluşturan bütün unsurlar da bu çarpık düzen içerisinde ezen-ezilen çatışmasını kuvvetlendirir. Nitekim Küçük Hasan'ın ayran yapıp, para kazanmak için tek sermayesi ihtiyar ve cılız bir keçidir. Küçük Hasan'ın en büyük korkusu ise, evdeki iki aç küçük midenin, kendi yokluğunda bu keçiyi yemesidir. Bu yönü ile Küçük Hasan ve onun bakmakla yükümlü 
olduğu iki küçük kardeş, kapitalizmin oluşturduğu çarpık düzen dolayısıyla medenileşememiş-insanlaşamamış olmalarıdır. Medeni hayatın adaletsiz davranması ve başkalarına sunduğu geniş imkânlarından mahrum bırakması dolayısıyla Küçük Hasan ve iki kardeşi, hikâye boyunca ilkel içgüdüleriyle hareket ederler. Hatta sistem, emeği ile para kazanmaya mecbur olan Küçük Hasan'1 adeta makineleştirmiştir.

5. Küçük Hasan'ın annesinin durumu ise toplumdaki bir başka çarpıklığın acı bir ifadesidir. Hikâyede nahiye merkezinde temizlikçi olarak çalıştığı belirtilen anne, hayatını idame ettirebilmek ve çocuklarına bakabilmek amacıyla muhtemelen bedenini satmak durumunda kalmakta ve onun yegâne sermayesi olan bedeni, erkekler tarafından sömürülmektedir. Kadın ve çocuklar bu sebepten dolayı çevreleri tarafından kabul görmemekte ve dışlanmaktadırlar. Bunun en büyük sebebi ise yine toplumdaki adaletsizliklerdir.

Sonuç olarak Sabahattin Ali, 1938 yılında kaleme aldığı "Ayran" hikâyesinde Toplumcu Gerçekçiliğin en temel unsurlarından olan ezen-ezilen çatışmasını kapitalizm ve emek kavramlarını çeşitli biçimlerde sembolize ederek gözler önüne serer. Yazarın, eserlerindeki kahramanları daha çok gerçekçi gözlemlerinden yola çıkarak kurgulaması ise onu Toplumcu Gerçekçiliğin klişelerinden sıyırarak, gözlemci ve eleştirel bir gerçekçilik boyutuna taşır. Bütün bu sebeplerden dolayı Sabahattin Ali, Toplumcu Gerçekçi Türk edebiyatının en özgün sanatçılarından biri olarak ön plana çıkar. 


\section{Kaynakça}

Bezirci, Asım (2007), Sabahattin Ali, İstanbul: Evrensel Basım Yayın.

Dalar, Tuba (2019), "Sultan Raev'in Timarhane'sinden Okunan Sovyet İdeolojisi”, Sosyal Bilimler Dergisi, S. 42, Ekim, s. 240-253.

Ertüzün, Reşit Mazhar (1985), Sabahattin Ali Olayının Gerçeği, İstanbul: Gür Yayınları.

Filiz Ali, Atilla Özkırımlı (1986), Sabahattin Ali, İstanbul: De Yayınevi.

Filiz Ali (1997), “Filiz Hiç Üzülmesin” Sabahattin Ali’nin Objektifinden Kızı Filiz'in Gözünden Bir Yaşam Öyküsü, İstanbul: Sel Yayıncılık.

İlhan, Ayşe Sitk1, Doğan Akın (1997), Sabahattin Ali’nin Özel Mektuplarl “İki Gözüm Ayşe”, Ankara: Bilgi Yayınevi.

Kahraman, Hasan Bülent (2004), Türk Şiiri, Modernizm, Şiir, İstanbul: Agora Kitaplığı.

Korkmaz, Ramazan (1997), Sabahattin Ali İnsan ve Eser, İstanbul: Yap1 Kredi Yayınlar1.

Köroğlu, Erol (2016), Türk Edebiyatı ve Birinci Dünya Savaşı 1914-1918, İstanbul: İletişim Yayınları.

Kutlu, Mustafa (1972), Sabahattin Ali, İstanbul: Dergâh Yayınları.

Lukacs, Georg (1987), Avrupa Gerçekçiliği, Çev. Mehmet H. Doğan, İstanbul: Payel Yay1nevi.

Moran, Berna (2003), Edebiyat Kuramları ve Eleştiri, İstanbul: İletişim Yayınları.

Oktay, Ahmet (2000), Toplumcu Gerçekçiliğin Kaynakları, İstanbul: Tüm Zamanlar Yayınc1lik.

Sabahattin Ali (2007), Yeni Dünya, İstanbul: Yap1 Kredi Yayınları.

Sülker, Kemal (1968), Sabahattin Ali Dosyası, İstanbul: Ant Yayınları.

Topuz, Hıfzı (2006), Başın Öne Eğilmesin Sabahattin Ali'nin Romanı, İstanbul: Remzi Kitabevi.

Yalçın, Alemdar (2003), Siyasal ve Sosyal Değişmeler Açısından Cumhuriyet Dönemi Türk Romanı (1946-2000), Ankara: Akçağ Yayınları. 